\title{
EFFECTIVE STUDENT FEEDBACK AS A MARKER FOR STUDENT SUCCESS
}

\author{
A. Cohen \\ LISOF (Pty) Ltd \\ Johannesburg, South Africa \\ e-mail: ashleigh@lisof.co.za

\section{Singh} \\ STADIO Holdings Ltd \\ Cape Town, South Africa \\ e-mail: divyas@stadio.co.za / https://orcid.org/0000-0003-4172-6273
}

\section{ABSTRACT}

Enhancing the learning journey of a student requires feedback that is thoughtful, relevant and indepth. Nicol (2010) as cited by UNSW Sydney (2018) stated that "feedback is valuable when it is received, understood and acted on. How students analyse, discuss and act on feedback is as important as the quality of the feedback itself'. This sentiment is echoed by Hattie (1999), also cited by UNSW Sydney (2018), when he stated that "feedback is the most powerful single moderator that enhances achievement". Feedback is one of the most important activities undertaken by educators in the realm of higher education. A student learning journey devoid of reliable, clear, consistent, and efficient feedback is a journey that is devoid of growth, cognitive development, intellectual challenge, and possibly even success.

The theoretical value and benefits of feedback in the teaching and learning process is welldocumented. Therefore, it is an epistemological conundrum when further evidence indicates that students' attitudes to feedback is either indifferent or totally negative. The feedback process is one of symbiosis between the educator and the student, with no one element of this relationship being more important than the other. The manner in which feedback is provided by the educator and the manner of engagement by the student determines the success of the process. A survey at a private higher education institution investigates the quality of feedback provided by educators and the extent to which the students on the receiving end engage with and act on the feedback received.

Keywords: student feedback, quality learning, students' voices, educators' perceptions, positive reinforcement, formative evaluation

\section{INTRODUCTION}

Naylor, Baik, Asmar, and Watty $(2014,3)$ indicate that "assessment and academic feedback are an essential part of learning in any context. Timely, detailed feedback ... helps people learn more effectively by providing a clear sense of where they are and what they have to do to 
improve." They further note that "there is a clear link between not providing feedback and student failure" (Naylor et al. 2014, 3). It is the process of feedback and the interpretation and internalisation of the same that promotes the student's journey towards success. The construct of feedback on assessment processes as a marker of student success is reinforced by Nicol $(2009,7-11)$ who notes that engagement with feedback leads to improvements in learning and ultimate success.

Cuseo (n.d., 1) suggests that student success may be evaluated from the perspectives of both the student and the educators within the institution of learning. It is, as stated by Cuseo (n.d., 1) the achievement of a "desirable student outcome" as a result of a successful student journey. Student success cannot be the fractured accumulation or culmination of tasks and events, but rather the journey of learning understood as a unit.

The journey towards success and graduateness encompasses the active process of both knowledge assimilation, as well as well as introspection and self-realisation garnered from feedback received throughout the learning experience.

Feedback is by far one of the most important activities undertaken by educators to facilitate student introspection and engagement with the academic, or learning, journey. It is an activity that promotes reflection and encourages action. Bellon, Bellon and Blank (1991, 277288) describe feedback in the academic space as follows:

"[A]cademic feedback is more strongly and consistently related achievement than any other teaching behaviour. ... this behaviour is consistent regardless of grade, socioeconomic status, race or school setting. ... When feedback and corrective procedures are used, most students can attain the same level of achievement as the top $20 \%$ of students."

This article aims to evidence that the process of providing and receiving feedback is only valuable when the feedback provided is of sufficient quality that it motivates students to engage with it and use it in a manner that, ultimately, contributes to a successful outcome. Nicol (2010, 1) notes, "how students analyse, discuss and act on feedback is as important as the quality of the feedback itself".

Vygotsky $(1978,84-91)$ points out that instruction is socially embedded and guidance by others is crucial for development. This article will demonstrate that, in order to optimise the feedback progression, educators must provide feedback in a way that is appropriate to the students' current level of development with respect to both empirical and theoretical knowledge. It is the ability of the educator to provide feedback that is scaffolded within a socially constructed arena and facilitates student engagement with and internalisation of knowledge and skill to result in a successful student journey (Copple and Bredekamp 2009, 8). 
The value of feedback in the teaching and learning environment to inform student development and success is well established in the literature. This article, however, will emphasise the students' general lack of engagement with the feedback that they receive, particularly with regards feedback aligned to assessment processes. It will further emphasise the responses of the educators with regards their role and abilities to provide feedback to students that is socially constructed and valuable. It is an underlying imperative of the teaching and learning construct that educators provide students with feedback that promotes critical engagement and demonstrates a practise of teaching and learning that is responsive and appropriate and facilitates the students' attainment of a successful outcome.

The over-arching purpose of this research is to unequivocally demonstrate that the provision of valuable and appropriate feedback by the educator is just as important as the manner in which the student engages with and acts on the feedback as part of the ongoing learning journey.

\section{LITERATURE REVIEW}

There has been much written about feedback in higher education, including its academic value, educator practices, and student perceptions and expectations. The literature clearly supports the construct of academic feedback in relation to assessment which is provided efficiently and effectively and engaged with from a student perspective, being aligned to the "successful student journey". For the purposes of this article, four areas pertaining to the provision of and engagement with feedback mechanisms have been chosen for deeper consideration. They are (i) the organic buy-in by educators and students to the mechanism and process of feedback, including the importance of student introspection and reflection, (ii) important concepts constituting assessment practice, (iii) understanding the link between feedback, the achievement of learning outcomes and student success ("graduateness"), and, most critically, (iv) students' perceptions of value in the feedback.

On the first issue, feedback in higher education is a process of engagement between student and educator. It should be an organic and interdependent process involving the interaction between the giver and the recipient with no one participant being more important than the other. Hattie (UNSW Sydney 2018, 3) distinguishes feedback as "the most powerful single moderator that enhances success and achievement." Similarly, Naylor et al. $(2014,4)$ urge that feedback be at the core of the learning curriculum if the student is to achieve even a modicum of success. Appreciating it as one of the most important activities that an educator undertakes, it is imaginable that an inadequate feedback system could result in the journey of learning and individual development transformation coming to nought (Naylor et al. 2014, 4). 
One of the most important requirements for effective feedback is the mutual effort and buy-in from both student and educator. The first key element identified under the concept of "effective feedback" is that of reflection and internalisation. Feedback must promote reflection and the desire of the student to act upon the outcomes of this process. It is during this process of reflection that the student can identify gaps in his learning and put mechanisms in place for improvement and the attainment of success. Understanding this principle also explains the need for authentic feedback to be embedded in all learning curricula and an ongoing, iterative activity throughout the learning journey. This is feedback which is constructed to set the student up for success in future learning and endeavours. Nicol's $(2010,1)$ sentiment pertaining to the analysis, discussion, and internalisation (and action) of feedback is deemed central to the learning journey.

In his work on assessment and feedback, Nicol $(2009,6)$ focuses on two dimensions which occur in what he describes as the "engagement-empowerment" realm and the "social-academic" territory. The reflection on the interconnectedness within and between these dimensions enables the student to internalise feedback and engage with it in a manner that is responsible and active (and, ultimately, valuable). This reflection results in a level of empowerment where the student manages his own learning in a way that promotes academic integration and a sense of identity and belonging, thereby creating an intrinsic level of motivation to engage in long-term learning processes extending beyond the realm of formal education. The concept of engagement that is empowering is echoed by Cuseo (n.d.) who includes, under the significant principles of student success, factors such as personal validation, self-efficacy, personal meaning, active involvement, and personal reflection.

On the second issue of important concepts constituting assessment practice, it is a historical misnomer that feedback is only distributed as part of a formal assessment event or process, either formative or summative. However, to be successful, the student must understand the value of assessment processes (both formal and informal, formative and summative) and the related feedback mechanisms. In conjunction with this, the educator needs to provide the student with feedback that facilitates the reflection process in a manner which promotes valuable learning and development throughout the learning journey. The receipt of valuable feedback on formative learning facilitates development as the student progresses towards the summative assessment event. The area of feedback relating to assessment has been interrogated by educationalists and researchers alike over many years and they predominantly link back to Bourdieu's (2008) construct of the reflexive process and the student's ability to engage with the feedback and act on this in a manner which supports future learning and achievement.

Nicol (2009) and Douglas (2007) emphasise the value of assessment with feedback, 
confirming that that formative assessments are the kinds of assessments that, when coupled with feedback, promote further learning. Formative assessments should be an ongoing occurrence in the learning process, with both formal and informal processes that include feedback which may be either written or verbal. The feedback is provided by the lecturer, peers, and/or the self, and may be both formal and informal. In all instances, if it is authentic and rigorous, it will have positive implications for the recipient and must inform the learning journey towards a successful outcome. Student reflection on and internalisation of feedback received results in empowering motivators that facilitates ongoing development and learning.

Feedback aligned to the formative assessment process is essential. It must be efficient and continuous and must promote a level of reflection that enables the student to learn from his mistakes and become motivated to work towards self-improvement. To this end, it is vital that educators provide feedback that is encouraging and fair. The feedback must be delivered in a manner that is devoid of judgement and is constructive.

The outcome of the formative feedback process is to close the "feedback loop" and the requirement is that the students make "some kind of response" to the feedback suggestions (Boud 2000, 158).

"This is one of the most often forgotten aspects of formative assessment. Unless students are able to use the feedback to produce improved work, through for example, re-doing the same assignment, neither they nor those giving the feedback will know that it has been effective." (Boud 2000, 158).

Summative assessments are those that take place at the end of the semester or the end of the year. It is these assessments that check the result of learning that has taken place after the teaching input is completed and these contribute to the indicators of success of the formative feedback activities. The summative assessment process is preceded by formative feedback activities that enable the students to participate in the summative task with confidence, skill and the requisite knowledge to result in a successful outcome.

Thirdly, for the feedback process to be effective, the student must be aware of the learning and assessment expectations. It is the understanding of this end goal that acts as a motivator for achievement as well as allowing for a mapping process of how to get there. Naylor et al. (2014) equate feedback to student-centred learning. The feedback process, they note, engages the student, and enables him to traverse his current situation and compare it with where he needs to be to achieve success. On the other hand, note Naylor et al. $(2014,5)$, "there is a clear link between not providing feedback and student failure".

The end goal and the achievement of success, must be underpinned by regular learning 
tasks and feedback mechanisms that promote reflection and self-motivation. The manner in which the educator delivers the feedback to the student, and the content of the feedback itself, is all important. In this regard, Pennington $(2012,2)$ demonstrates the unmistakeable impact of educator and institutional practices on student success. Institutions, notes Pennington $(2012,2)$, can directly affect student success through educator support, engagement, and customised feedback or, as noted by Nicol $(2009,6)$, the student most eligible for success is "he who is engaged, empowered and has the ability to develop objectivity in monitoring, management and self-assessment/self-regulation". It is important that students understand how they are to be assessed and the type of feedback that they will receive. It is important too that the students are made aware of the need to engage with, reflect on and action all aspects of the feedback received so as to improve future learning and enhance the opportunity for success.

Fourthly, feedback is only deemed valuable if perceived as such by the student on the receiving end. The student needs to be engaged with the feedback process and must realise that feedback is not limited to what is received from the educator post assessment evaluation. The feedback provided by the educator should support pedagogic practice and should be articulated in a manner that processes insight and an improvement in future learning. The usefulness of the feedback can be determined by the extent to which it is internalised and applied by the student (Douglas 2007, n.p.).

Research shows that individualised assessment feedback is far better received by students and that - not unexpectedly - students are more distrustful of standardised comments, particularly those that are received online (Douglas 2007, n.p.). In the current era of increased online learning, online assessments, and online marking this may be rather significant. Addressing the matter, Douglas (2007, n.p.) recommends that for standardised or generic feedback to realise value, the feedback must be supplemented with engagement and discussion at an individual level.

Students in higher education are expected to be self-directed in their learning processes. However, Hassel and Ridout $(2018,2)$ point out that "... the transition from the highly controlled, teacher-driven learning environment of schools ... to university, where the student is responsible for their own learning, is perhaps the biggest challenge for the students." This requires significant adjustment on the part of the student and well thought-out guidance on the part of the educator. One instance of the guidance element is rendered in the form of feedback: feedback that is fair, positive, developmental, and encouraging. Making mistakes is a part of the students' learning process. Learning from errors made facilitates self-development. Educators are required to deliver feedback in a constructive and non-judgemental manner: "[t]he secret is to use error constructively, to root out mistakes and misconceptions and correct 
them" (Naylor et al. 2014, 5). In this regard, the educator needs to be conscious and understanding of, and engage with, the differences surrounding developmental versus deficitdriven approaches to feedback, recognising that the latter often result in less reflexive, introspective processes.

The literature is clear with regards the expectations of feedback aligned to assessment processes. The researchers all concur that the students' development towards a successful outcome requires engagement with and reflection on feedback received and feedback that is valuable, constructive and empowering. The challenge, however, faced by institutions of higher learning is the provision of individualised feedback that promotes student internalisation and action as well as the inclination and motivation of the student to engage with such feedback when received.

\section{RESEARCH METHODOLOGY}

The research methodology for this article is underpinned by a constructivist approach. Constructivism, states Koshy $(2010,33)$ focuses on the subjects' - in this case the students' and the educators" - account and interpretation of knowledge which is "not passively received, but actively built up by the subject" in a manner that is adaptive and "serves the organisation of the experimental world". It is important to use a constructivist approach for this research as it supports an ontological position that views the social phenomenon of feedback as one which is socially constructed by the students and educators. Social constructivists in institutions of higher learning are required to encourage a developmental approach where students "view problems and issues from different angles. Knowledge which is constructed when students form their own interpretations" (Scheurman 1998, 1).

The constructivist approach was employed for the purpose of understanding feedback mechanisms and the provision and engagement therewith at a private higher education institution in South Africa. It is this approach that allows for the development of insight and understanding into how feedback processes either facilitate or disable engagement, reflection and action for the purpose of a successful learning journey.

The data for the purpose of this study was collected from both students and educators. The student sample was randomly drawn from the second-year cohort of students studying towards a three-year qualification in the discipline of fashion. The decision was made to use second year students as they had already been in higher education for at least one year and had been exposed to various feedback models, all of which informed their engagement and participation in the study. The study further targeted full-time educators at the same private higher education institution as the student sample. The educators selected for participation in the research had 
more than one year of lecturing experience and had previous exposure to and engagement with different feedback models.

The research tools used for the purpose of this research included a paper-based questionnaire for the student sample and an online questionnaire for the educator sample. The students were provided with paper-based questionnaires as the institution of higher learning surveyed operated in the contact mode of delivery and not all students have access to online resources. All questionnaires were completed anonymously by the participants thereby eliminating bias.

The questionnaire disseminated to the students explored their perceptions of the role of feedback in development transformation and success. Students were surveyed with regards to the type and extent of feedback received by educators, the perceived value of the feedback and the extent to which they engages with and acted on the feedback received. The questionnaire disseminated to the educator sample surveyed elements including:

Section 1: The understanding of direct and indirect corrective feedback.

Section 2: The characteristics of feedback relating to assessment mechanisms.

Section 3: The ability of the educator to provide feedback.

Section 4: The skill of the educator to provide feedback in line with requisite characteristics.

Section 5: The employment of feedback as a reflexive tool.

Section 6: The employment of feedback as a developmental tool.

Section 7: The use of feedback in teaching and learning.

Section 8: Different types of feedback employed by educators.

The variables identified for inclusion in the student and educator samples were such that they facilitated a depth and breadth of understanding of the feedback processes employed by the educators at the private higher education institution and the extent to which the students in the sample found the feedback to be useful, valuable and engaging for a successful outcome.

\section{RESULTS AND ANALYSIS}

It is important to note that although the two components of the research were conducted six months apart, they were conducted within the same academic cycle. For the purpose of this article, the results from both respondent samples have been combined (where feasible) to ensure a consolidated approach to the study. The study links experiences, practices, perceptions, and responses of both sample sets to provide an over-arching view of feedback practices in the institution in relation to the student journey and the achievement of learning objectives. 
Thirty-one per cent of the student population participated in the study. This equated to 55 of the 179 second year students. Fifty-seven full-time educators (with a minimum of one year's experience lecturing at a higher education level) were invited to participate in the study. Only 10 educators $(17.5 \%)$ completed the online survey. Although the educators' response rate was lower than that elicited from the student sample, the findings were non-the-less interesting and relevant to the study.

Fifty-one per cent of the students who participated in this study indicated that they received regular feedback from their educators. The fact that 49 per cent of the sample perceived the receipt of feedback to be either irregular or non-existent raises a concern about the amount and regularity of the feedback provided by the institution surveyed. The literature clearly demonstrates that feedback must be given to students regularly in order to have a positive impact on the student journey. The student sample further indicated that 63 per cent of the feedback received was verbal with only 37 per cent received in the written form. In stark contrast to this, 80 per cent of the educator sample believed that they provided verbal feedback 80 per cent of the time. Of the overall student population, only 30 per cent perceived the feedback received as focused and individualised thus indicating that 70 per cent of the sample view feedback as generic with a "one-size-fits-all” approach.

Overall, 55 per cent of the students indicated that they did not interrogate feedback received in their formative assessment activities, lending credence to the opinion that students do not attribute value to feedback on assignments. This result is interesting and in direct contrast to the findings of Douglas, Salter, Dowlman and Eri $(2016,8)$, who found that students tended to regard feedback "only in terms of information provided to them as part of an assessment." Dison, Shalem and Langsford $(2019,86)$ noted in their study that "students reported discussing comments and feedback made by lecturers on their assignments. This included reading the lecturer's comments (between 78 and $83 \%$ of the respondents) or discussing the assessment with their peers (between 44 and $50 \%$ of the respondents)."

The student responses in this study, however, require further interrogation as the students' responses may also highlight a deeper issue, namely, the quality of the feedback provided in the formal assessment process. The study did not ask for reasons why students did not interrogate the feedback in the formal assessments. The respondents in this study also failed to see the relationship between feedback and relevance to successful learning outcomes, and they do not view the feedback process as one that is empowering. Nicol $(2009,18)$ discusses the construct of "academic empowerment" and the relationship between engagement and empowerment where students "take responsibility for their own learning" thereby directing their own journey towards success. 
The regularity or frequency of feedback received by the student sample and whether this was provided and received in either verbal or written format is summarised in Figures 1 and 2.

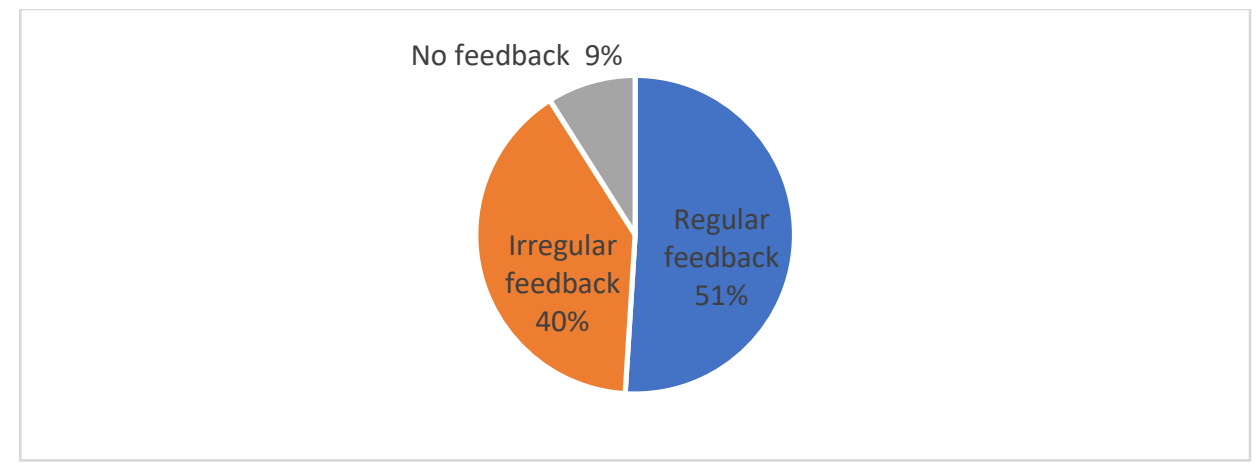

Figure 1: Student report on feedback received by educators

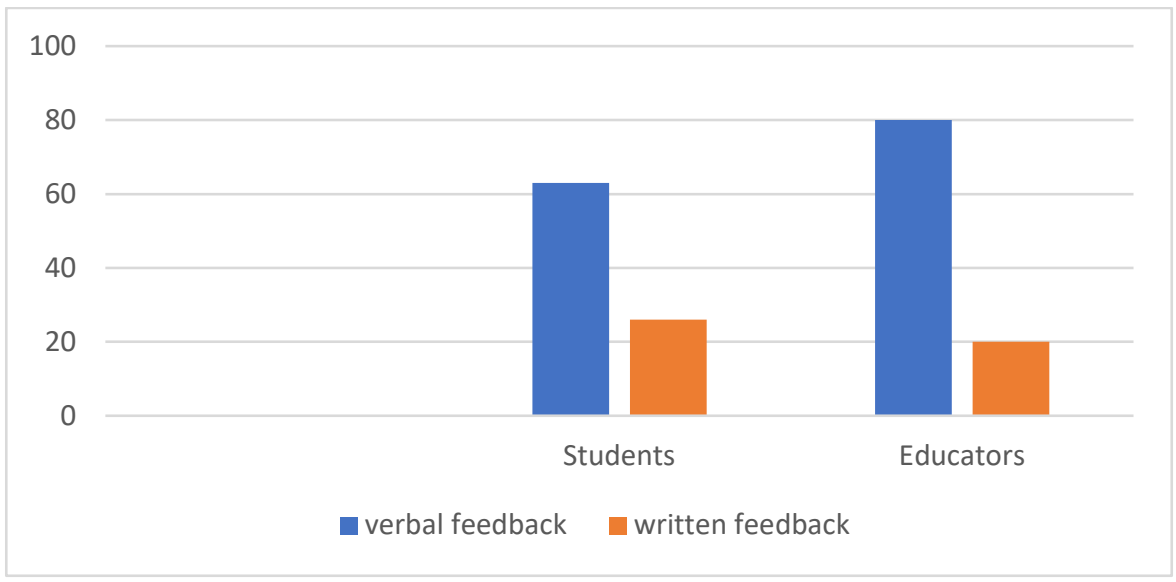

Figure 2: Written vs Verbal feedback

Within the educator sample, the overarching view is that informal feedback in the contact space, offers students the most value - far greater than feedback provided within the limited realm of assessments. Half of the educator sample stated that feedback during individual conversations between student and educator are "most valuable". This finding is aligned with the data collected from the student sample. Only 38 per cent of the educator respondents in this sample, however, provide written feedback during the assessment process. This low level of assessment-based feedback may also be a significant contributor to the fact that 60 per cent of the students indicated that they did not interrogate assessment-based feedback. Feedback is only interrogated by the student if it is deemed to be valuable and to provide him with the scaffolding that will result in self-development and a successful outcome.

The student respondents highlighted the need for feedback that is specific and individualised and, hence, promotes engagement. Seventy-six per cent of the students in the sample believe that the feedback received by the educators could be more useful. This contrasts 
with the educator sample where 80 per cent of the respondents believed that they are highly skilled at employing feedback mechanisms that close the gap between actual and desired performance. Quite clearly, there is a material dissonance between the students and educators on what constitutes "useful" feedback, and this requires urgent attention at the institutional level.

The educators were surveyed in terms of the characteristics of the feedback provided to students and for their skills in providing feedback. Seventy per cent of the educators in the sample believe that they are "highly skilled at providing feedback that is relevant," yet 50 per cent of them said that they provided feedback that "promotes reflexive processes that are valuable," and 40 per cent of them provided feedback that is "transparent and educational". This is all, theoretically, aligned to the concept that feedback provided by educators is such that it motivates the students to engage with, reflect on and action the feedback in a manner that promotes self-development and the attainment of success.

Table 1: Outcome of feedback provided in which educators are "Highly Skilled"

\begin{tabular}{|c|c|}
\hline Outcome of Feedback Provided & Percentage of Educators "Highly Skilled" \\
\hline Valuable & 50 \\
\hline Reflexive & 50 \\
\hline Educational & 40 \\
\hline Valid & 60 \\
\hline Reliable & 60 \\
\hline Relevant & 70 \\
\hline Transparent & 40 \\
\hline
\end{tabular}

Based on the data from the educator sample, it was not surprising that the student respondents felt that the amount of written feedback received was inadequate. Furthermore, they noted that when written feedback was provided, it tended to be generic rather than individualised and focused. The student responses indicate that students believe that this type of feedback is deficit (error) based and does not provide developmental guidance for future learning. This is corroborated by Naylor et al. $(2014,5)$ who indicate that feedback must be "developing, encouraging and fair". They go on to say that "error is inevitable; it is how students learn. The secret is to use that error constructively, to root out mistakes and misconceptions and correct them" (Naylor et al. 2014, 5). This is further corroborated by the statistically high number of students who do not interrogate (and hence apply) feedback received.

Feedback provided to students may be deficit (error) based, but must be sufficiently expansive and developmental to enable students to engage with errors made and reflect on improvement mechanisms. The guidance provided by the educator must take note of the evident 
knowledge and/or skill gaps and provide the students with guiding mechanisms that promote future learning and the rectification of error. Sixty-two per cent of the student respondents, however, view deficit (error) based feedback as demotivating and not valuable. Table 2 details the variables surveyed in the educator sample together with the data findings. It is evident from this data that the educators view the construct and characteristics of feedback as an essential component of the teaching and learning process, although the extent to which the feedback is used to achieve a specified objective varies.

Table 2: Research variable and data finding: Characteristics of feedback

\begin{tabular}{|l|c|}
\hline \multicolumn{1}{c|}{$\begin{array}{c}\text { Variable Researched: } \\
\text { Assessment feedback is... }\end{array}$} & Data Finding ** \\
\hline Neutral, unbiased \& objective & $90 \%$ agree; $0 \%$ disagree \\
\hline Irrefutable & $20 \%$ agree; $60 \%$ disagree \\
\hline Accurate & $100 \%$ agree; $0 \%$ disagree \\
\hline Relates to marks achieved & $70 \%$ agree; $10 \%$ disagree \\
\hline Is a consequence of performance & $50 \%$ agree; $20 \%$ disagree \\
\hline Constructive & $90 \%$ agree; $0 \%$ disagree \\
\hline Challenging & $50 \%$ agree; $20 \%$ disagree \\
\hline Information to guide future performance & $80 \%$ agree; $0 \%$ disagree \\
\hline Is immediately provided ${ }^{*}$ & $50 \%$ agree; $0 \%$ disagree \\
\hline Availability is delayed & $10 \%$ agree; $10 \%$ disagree \\
\hline
\end{tabular}

${ }^{*}$ From the responses received, it would appear that there was a lack of clarity regarding these two variables. With reference to "immediately provided" $50 \%$ of the respondents answered "neutral" and in "availability is delayed", $80 \%$ of the respondents answered "neutral".

** The data findings to not add up to $100 \%$ as there was a "neutral" response on the questionnaire which has not been indicated here.

Areas in the provision of feedback that require an upskilling process for the educators are detailed in Table 3.

Table 3: Research variable and data finding: Areas of Feedback Not Evident in Teaching and Learning

\begin{tabular}{|l|l|}
\hline \multicolumn{1}{|c|}{ Variable Researched } & Data Finding \\
\hline Provision of feedback & $10 \%$ not evident in teaching \& learning \\
\hline Feedback to promote reflexive processes & $20 \%$ not evident in teaching \& learning \\
\hline Feedback to promote knowledge construction & $30 \%$ not evident in teaching \& learning \\
\hline Feedback to close the gap between actual \& desired performance & $20 \%$ not evident in teaching \& learning \\
\hline Feedback to promote dialogue & $30 \%$ not evident in teaching \& learning \\
\hline Feedback for the purpose of coaching & $50 \%$ not evident in teaching \& learning \\
\hline
\end{tabular}

Eighty per cent of the participating educators believe that they are highly skilled at employing feedback mechanisms that close the gap between actual and desired performance. It is evident from this body of research that educators view the construct and characteristics of feedback as an essential component of the teaching and learning process, although the extent to which the feedback is used to achieve the specified objectives varies. 
The research confirms the importance of educators being sufficiently knowledgeable to provide students with feedback that is valuable, actionable, and which leads to a successful learning journey. It is furthermore a criterion to which educators and students have aligned ideas as to what feedback should look like and the purpose it should serve.

\section{RECOMMENDATIONS}

This research study provides valuable insights for the private higher education institution surveyed. From the research study of student voices and educator responses and a scan of the literature, a checklist for effective feedback that promotes student success and graduateness was developed. This checklist is aligned with the four key areas identified earlier as underpinning feedback, namely, that good feedback practices should (i) promote introspection and reflection, (ii) be linked to sound assessment practices, (iii) realise learning outcomes and attributes of graduateness, and (iv) be perceived by the student as being of value. The integrated matrix recommended for use is set out in Table 4.

Table 4: Principles that enhance student feedback and engagement practices (Naylor et al. 2014; Douglas 2007)

\begin{tabular}{|c|c|c|c|c|}
\hline \multirow{2}{*}{$\begin{array}{l}\text { Characteristics of effective } \\
\text { feedback (Naylor et al. 2014; } \\
\text { Douglas 2007) }\end{array}$} & \multicolumn{4}{|c|}{ Link to the four key areas of effective feedback } \\
\hline & $\begin{array}{l}\text { Introspection } \\
\& \text { reflection }\end{array}$ & Assessment & $\begin{array}{c}\text { Learning } \\
\text { outcomes \& } \\
\text { graduateness }\end{array}$ & Value-adding \\
\hline \multicolumn{5}{|l|}{ Effective feedback must: } \\
\hline Improve skill and learning & & & & $\mathrm{X}$ \\
\hline $\begin{array}{l}\text { Include model answers where } \\
\text { practicable }\end{array}$ & & $\mathrm{X}$ & & \\
\hline Provide constructive criticism & $\mathrm{X}$ & & & \\
\hline Encourage two-way communication & & & $\mathrm{X}$ & \\
\hline $\begin{array}{l}\text { Promote knowledge acquisition } \\
\text { through active learning }\end{array}$ & & $\mathrm{X}$ & & \\
\hline $\begin{array}{l}\text { Promote student responsibility and } \\
\text { accountability }\end{array}$ & $\mathrm{X}$ & & $\mathrm{X}$ & \\
\hline Support pedagogic practice & & $\mathrm{X}$ & & $\mathrm{X}$ \\
\hline \multicolumn{5}{|l|}{ Effective feedback must be: } \\
\hline Valid and reliable & & & & $\mathrm{X}$ \\
\hline Consistent & & $\mathrm{X}$ & & $\mathrm{X}$ \\
\hline $\begin{array}{l}\text { Encouraging, provide guidance and be } \\
\text { fair }\end{array}$ & $\mathrm{X}$ & $\mathrm{X}$ & & \\
\hline Clear and understandable & $\mathrm{X}$ & & & \\
\hline $\begin{array}{l}\text { Ongoing, continuous and promote } \\
\text { improvement in cycles of feedback that } \\
\text { feed from one assessment to the next }\end{array}$ & $\mathrm{X}$ & $\mathrm{X}$ & & $\mathrm{X}$ \\
\hline $\begin{array}{l}\text { Non-judgemental and focussed on } \\
\text { performance rather than personal traits }\end{array}$ & $\mathrm{X}$ & & & \\
\hline Motivating and encouraging & $\mathrm{X}$ & & & $\mathrm{X}$ \\
\hline Personalised and detailed & $\mathrm{X}$ & & & \\
\hline Timely & & & & $X$ \\
\hline Deficit (error) based & $X$ & & & \\
\hline
\end{tabular}


The identified characteristics enable a simple mapping process that embraces good feedback processes by both the educator and the student. It is recommended, therefore, that this mapping process is used by the institution as a lens to facilitate high quality feedback and engagement practices, promoting academic quality, student support, and holistic success and graduateness. It is the symbiotic relationship between the student and the educator that will enhance the value attributed to feedback. The value of the feedback process lies with both participants where neither one is more important than the other.

\section{CONCLUSION}

There is no gainsaying the significance of effective feedback in the process of teaching and learning. Theorists reviewed for the purpose of this study all concur that feedback provided to students that promotes reflection and action is more likely to result in development and a positive learning journey. Engaging with students' voices and educators' perceptions of feedback provides powerful insight into exactly how the construct of feedback is engaged with at the level of higher education. This reminds us that how it is being done is not necessarily effective or the most constructive way to result in success.

At a practical level, social constructivists like Segers (2008) as cited in Thurlings, Vermeulen, Bastiaens and Stijnen $(2013,13)$ demonstrate that the students' perception of the feedback received influences approaches to learning. Students who demonstrate a more positive regard for the feedback process, are more likely to approach their learning in a deep and meaningful manner by actioning feedback received for the purpose of self-development. Martens, Brabander, Rozendaal, Boekaerts and Van der Leeden (2010, 316) succinctly summarise the value of effective feedback highlighting the fact that positive feedback "has been generally found to enhance intrinsic motivation". These students are more likely to interrogate feedback, action the feedback and thereby close the gap between current and desired performance. It is this student who will be more likely to graduate from his studies and transfer into the world of work with skills and knowledge that are desirable and sought-after. Overtly bringing to the fore the educators' perception of their skill at providing feedback and the students' perception of the efficacy of and their engagement with this feedback, will surely create a future shift in this practice at the level of higher education.

\section{REFERENCES}

Bellon, J. J., E. C. Bellon and M. A. Blank. 1991. Teaching from a research knowledge base: A development and renewal process. New Jersey: Prentice Hall. doi:10.12691/education-6-6-16.

Boud, D. 2000. Sustainable assessment: Rethinking assessment for the learning society. Studies in Continuing Education:151-167. doi:10.1080/713695728. 
Bourdieu, P. (Ed.). 2008. Key concepts. Durham, Acumen Publishing Limited. doi:10.1080/014256904200026989.

Cuseo, J. n.d. Student success: Definition, outcomes, principles and practices. Marymount College. http://indstateedu (Accessed 15 September 2018).

Copple, C. and S. Bredekamp. 2009. Developmentally appropriate practice in early childhood programs. ERIC. https://eric.ed.gov/?id (Accessed 18 November 2019).

Dison, L., Y. Shalem and D. Langsford. 2019. Resourcefulness matters: Student patterns for coping with structural academic challenges. South African Journal of Higher Education 33(4): 76-93. http://dx.doi.org/10.20853/33-4-2831 (Accessed 29 May 2020).

Douglas, M. F. 2007. Enhancing student learning using online submission and feedback to improve first year learning experience. Paper presented at the Business, Management, Accountancy \& Finance Conference, 2-4 May 2007. Birmingham. http://www.reap.ac.uk/reap/public/papers (Accessed 14 July 2018).

Douglas, T., S. Salter, M. Dowlman and R. Eri. 2016. The feedback process: Perspectives of first and second year undergraduate students in the disciplines of education, health science and nursing. Journal of University Teaching and Learning Practice 13(1): 1-19. https://ro.uow.edu.au/jutlp/ vol13/iss1/3 (Accessed 29 May 2020).

Hassel, S. and N. Ridout. 2018. An investigation of first-year students' and lecturers' expectations of university education. Frontiers in Psychology 8(22): 1-13. doi:10.3389/fpsyg.2017.02218.

Koshy, V. 2010. Action research for improving education practice: A step-by-step guide. $2^{\text {nd }}$ Edition. London: Sage Publications.

Martens, R., C. de Brabander, J. Rozendaal, M. Boekaerts and R. van der Leeden. 2010. Inducing mind sets in self-regulated learning and motivational information. Educational Studies 36(3): 311-327. www.researchgate.net/publication/248968680_inducing_mind_sets_in_self-regulating_learning (Accessed 25 May 2020).

Naylor, R., C. Baik, C. Asmar and K. Watty. 2014. Good feedback practices: Prompts and guidelines for reviewing and enhancing feedback for students. Melbourne. http://Melbourne-cshe.unimelb. edu.au/data (Accessed 14 July 2018).

Nicol, D. 2007. Principles of good assessment and feedback: Theory and practice. www.York.ac.uk/ media (Accessed 15 July 2018).

Nicol, D. 2009. The first year experience: Transforming assessment and feedback: Enhancing integration and empowerment in the first year. Mansfield, UK: The Quality Assurance Agency for Higher Education. http://dera.ioe.ac.uk/11605/1 (Accessed 15 July 2018).

Nicol, D. 2010. From monologue to dialogue: Improving written feedback processes in mass higher education, assessment and evaluation in higher education 35(5): 501-517. www.tandfonline.com/ doi/abs/10.1080/02602931003786559 (Accessed 15 July 2018).

Pennington, H. 2012. For student success, stop debating and start improving. The Chronicle of Higher Education. Bill \& Melinda Gates Foundation. https://www.chronicle.com. (Accessed 7 September 2018).

Scheurman, G. 1998. From behaviorist to constructivist teaching. Social Education 62(1). www.socialstudies.org/sites/default/files (Accessed 25 May 2020).

Thurlings, M., M. Vermeulen, T. Bastiaens and S. Stijnen. 2013. Understanding feedback: A learning theory perspective. Educational Research Review 9: 1-15. https://www.pure.tue.nl/ws/files (Accessed 1 January 2020).

UNSW Sydney. 2018. Giving assessment feedback. www.teaching.unsw.edu.au (Accessed 22 July 2018).

Vygotsky, L. 1978. Mind in society: The development of higher psychological processes. San Diego: University of California. 